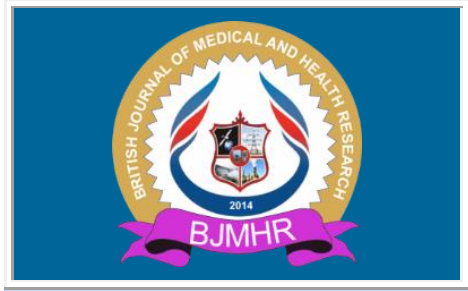

\title{
BJMHR
}

British Journal of Medical and Health Research

Journal home page: www.bjmhr.com

\section{CT Thorax Evaluation In Connective Tissue Disorders}

\author{
B.K.Duara,Vineeth Skariah Abraham* \\ Department of Radiology, Gauhati Medical College and Hospital, Guwahati, India
}

\section{ABSTRACT}

High Resolution Computed Tomography is a non-invasive technique for evaluating patients with clinically diagnosed Connective Tissue Disorders and plays an important role in detecting early morphologic changes in patients with suspected pulmonary disorders such as interstitial lung disease and bronchiectasis. Aims of this study were to evaluate the High Resolution Computed Tomography thorax findings and identify specific patterns of involvement in different connective tissue disorders The study was done as a hospital based cross sectional descriptive study comprised of 60 consecutive patients who were clinically diagnosed with a connective tissue disorder from April 2018 to March 2019 for a period of 12 months in the Department of Radio diagnosis, Gauhati Medical College and Hospital, Guwahati. Graphpad instat 3 software and paired t test were used in the calculation. Most common Interstitial lung disease pattern was Nonspecific Interstitial Pneumonia (33\%), followed by Usual Interstitial Pneumonia (16.7\%) pattern. But significantly higher incidence of Usual Interstitial Pneumonia pattern and bronchectatic changes was noted in Rheumatoid Arthritis as compared to other Connective Tissue Disorders ( $\mathrm{p}$ values 0.0016 and 0.0148 respectively). There is significantly high percentage of pleural effusion in patients presenting with Systemic Lupus Erythematosus ( $\mathrm{p}$ value 0.0044 ). There is also significantly higher occurrence of esophageal dilatation in patients with Systemic Sclerosis (p value 0.0001). High Resolution Computed Tomography evaluation is of immense importance and utility in understanding the extent and type of pulmonary involvement and in distinguishing the pattern of interstitial lung disease in different Connective Tissue Disorders.

Keywords: ILD: Interstitial lung disease, Connective Tissue Disorders, HRCT: High Resolution Computed Tomography, UIP: Usual Interstitial pneumonia, NSIP; Nonspecific Interstitial pneumonia. 


\section{INTRODUCTION}

HRCT is the imaging method of choice for patients with CTD, demonstrating the presence, distribution and characteristics of disease with higher sensitivity than conventional chest radiographs ${ }^{5}$. Connective tissue diseases (CTD), also known as collagen vascular diseases are a heterogeneous group of autoimmune disorders. These diseases are multi systemic and can affect any organ system ${ }^{1}$

Mostly this term is used to denote the autoimmune disorders which are classified as the systemic rheumatic diseases. This group includes Rheumatoid arthritis (RA), Systemic Lupus Erythematosus (SLE), Primary Sjögren's syndrome (SS), Primary systemic sclerosis (PSS), Polymyositis- Dermatomyositis (PM-DM) and Mixed Connective Tissue Disease (MCTD) ${ }^{2}$. (Ref Table 1)

Table 1: Percentage of Connective tissue Diseases in the study participants

\begin{tabular}{lll}
\hline Connective tissue disorder & No. of Cases & Percentage \\
\hline Rheumatoid arthritis & 26 & 43.33 \\
SLE & 13 & 21.67 \\
Systemic sclerosis & 9 & 15.00 \\
Sjögren's syndrome & 4 & 6.67 \\
MCTD & 4 & 6.67 \\
Dermatomyositis-Polymyositis & 4 & 6.67 \\
Total & 60 & 100.00 \\
\hline
\end{tabular}

HRCT is the imaging technique of choice for evaluation of patients with connective tissue diseases, demonstrating the presence, gross characteristics and distribution of pulmonary disease with greater sensitivity than conventional chest radiographs. In certain clinical circumstances, HRCT findings can suggest a specific diagnostic process. HRCT often allows the predominant process to be identified. However, it has some limitations. In many cases, HRCT appearance is nonspecific and may or may not be related to an underlying CTD (3). Thus, radiologic findings should never be interpreted without knowledge of the clinical picture. The best approach to evaluate connective tissue disease is to recognize and analyze different patterns of involvement, which include pulmonary, pleural and mediastinal or hilar lymph node involvement. Interstitial lung disease (ILD) is a challenging clinical entity that can be associated with multiple CTDs. Early and correct diagnosis of pulmonary involvement in Connective tissue diseases is important because of its therapeutic and prognostic implications. Prompt treatment often lead to improved outcomes ${ }^{3}$.

The two CT findings which are mostly responsible for a large part of the mortality and morbidity in this patient group are pulmonary arterial hypertension and interstitial lung disease 4 
HRCT often allows the predominant process to be identified. However, it has some limitations. In many cases, HRCT appearance is nonspecific and may or may not be related to an underlying $\mathrm{CTD}^{5}$

\section{MATERIALS AND METHOD}

This cross sectional study comprised of 60 consecutive patients who were clinically diagnosed as a connective tissue disorder. Institutional ethics Committee number was MC/190/2007/Pt1/1EC/58. Sample size was calculated using the prevalence variable ${ }^{6}$

The minimum sample size is 60 .

$$
\mathrm{N}=\mathrm{Z}^{2} \times \mathrm{p}(1-\mathrm{p}) / \mathrm{d}^{2}
$$

Both in-patients and out-patients attending Gauhati Medical College and Hospital, Guwahati were taken up for study. The study was conducted from April 2018 to March 2019 for a period of 12 months in the Department of Radiodiagnosis, Gauhati Medical College and Hospital. All patients clinically diagnosed as a connective tissue disorder were subjected for CT thorax evaluation. Clinical diagnosis was based on history, examination and blood tests.

\section{Data Collection and Procedure:}

A detailed history of all the patients was taken and clinical obvious signs and symptoms and risk factors documented on a pre typed proforma. All the patients underwent routine blood investigation and other investigations. However, this did not form a part of the study. All the patients were subjected to CT thorax evaluation after taking informed consent for the same.

\section{Inclusion criteria:}

1) Patients referred to the Department of Radiology with clinically diagnosis of connective tissue diseases. Informed consent to participate the test was prerequisite.

2) Patients of all age groups

\section{Exclusion criteria:}

1) Patients who are unwilling to participate in the study.

2) Pregnant patients

Informed consent was taken from the patient/ guardian of patients enrolled in the study. The CT thorax examination was done using Phillips MX16, 16 slice CT scan system and its results were recorded in a structured format.

Slice thickness/ increment: $1 \mathrm{~mm} / 0.5 \mathrm{~mm}$

Scanning area; Lung apex to adrenal glands

Window centering: -700 (lung window), 50(mediastinal window)

Window width: 1500(lung window), 350 (mediastinal window)

Voltage: $120 \mathrm{KV}$

\section{Statistical analysis}


Findings were subjected to standard statistical analysis using graph pad Instat version 3 software. Findings were analyzed using tests of significance and p value is calculated. Results were analyzed and logical conclusions were drawn

\section{RESULTS AND DISCUSSION}

In this cross sectional descriptive study, sixty patients who were diagnosed of Connective Tissue Disorder were examined with HRCT thorax after taking informed consent. Out of 60 patients, 48 patients were females showing a 4:1 preponderance. (Ref Table 2)

Table 2: Sex distribution of study participants

\begin{tabular}{llll}
\hline Disease & Female N(\%) & Male N(\%) & Total N(\%) \\
\hline Rheumatoid arthritis & $20(77 \%)$ & $6(77 \%)$ & $26(100 \%)$ \\
SLE & $11(85 \%)$ & $2(15 \%)$ & $13(100 \%)$ \\
Systemic sclerosis & $8(88 \%)$ & $1(12 \%)$ & $9(100 \%)$ \\
Sjögren's syndrome & $3(75 \%)$ & $1(25 \%)$ & $4(100 \%)$ \\
MCTD & $3(75 \%)$ & $1(25 \%)$ & $4(100 \%)$ \\
\hline
\end{tabular}

Maximum numbers of patients were from the age group 51-60 years (31.6\%) with 53 patients (88.4\%) above the age of 40 years.(Ref Figure 1).The Mean age of males is 55.3 years and of females is 54.4 years.

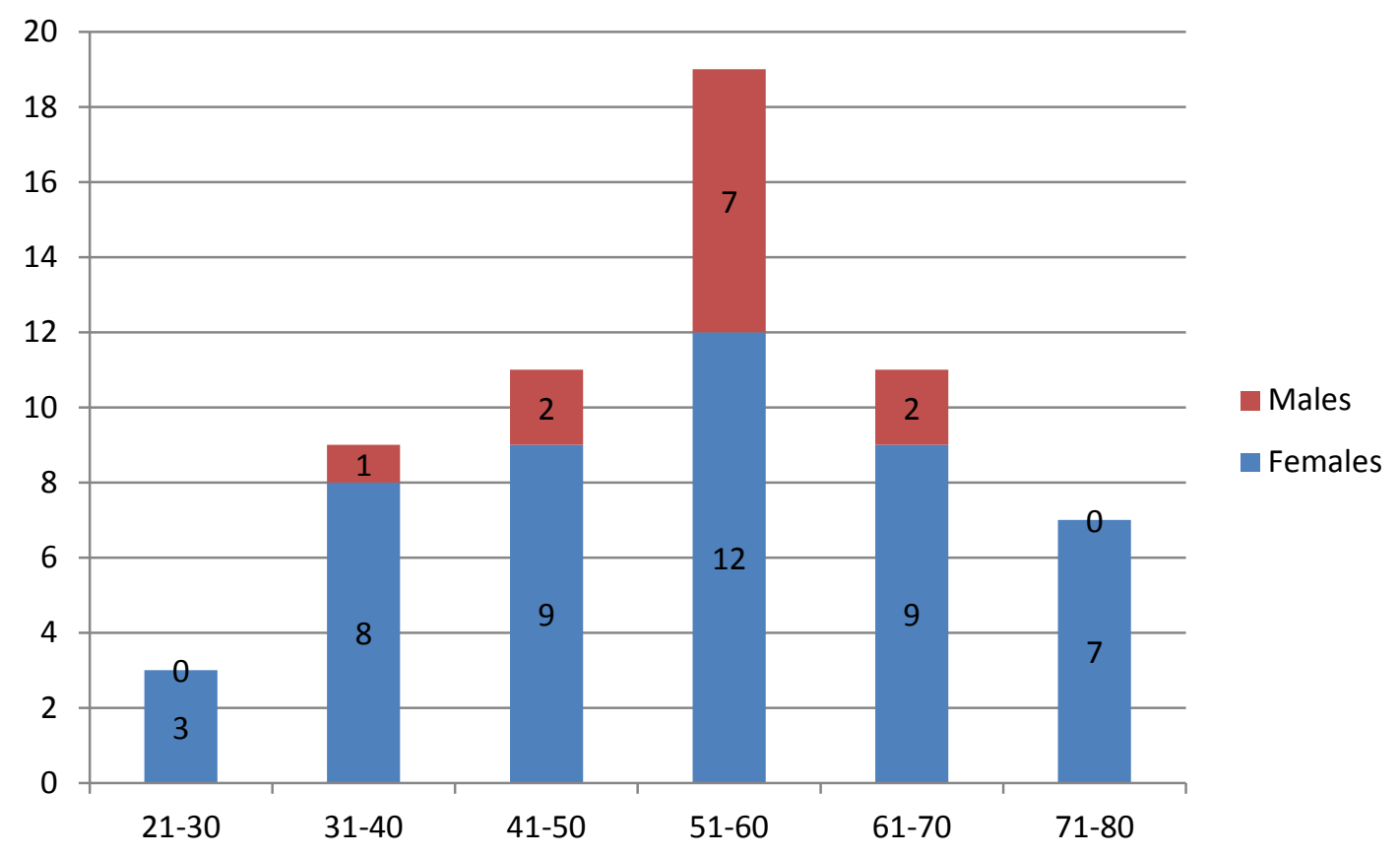

Figure 1: Sex distribution of patients per age group

Most patients had RA (26 patients/ 43.3\%) which was followed by SLE in 13 patients (21.6\%). In our study the most common presenting symptom in patients was breathlessness which constituted $80 \%$ of patients. (Ref Figure 2) 


\section{Symptoms}

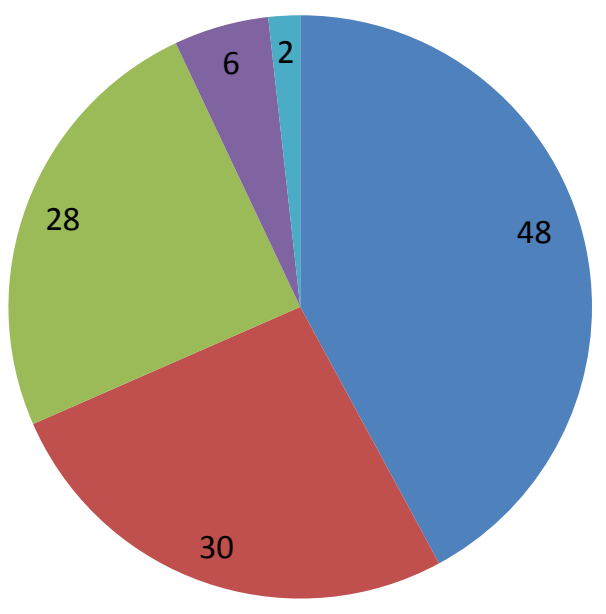

$$
\begin{aligned}
& \text { Breathlessness } \\
& \text { Cough } \\
& \text { Fever } \\
& \text { Chest pain } \\
& \text { Hemoptysis }
\end{aligned}
$$

Figure 2: Clinical symptoms in the study participants
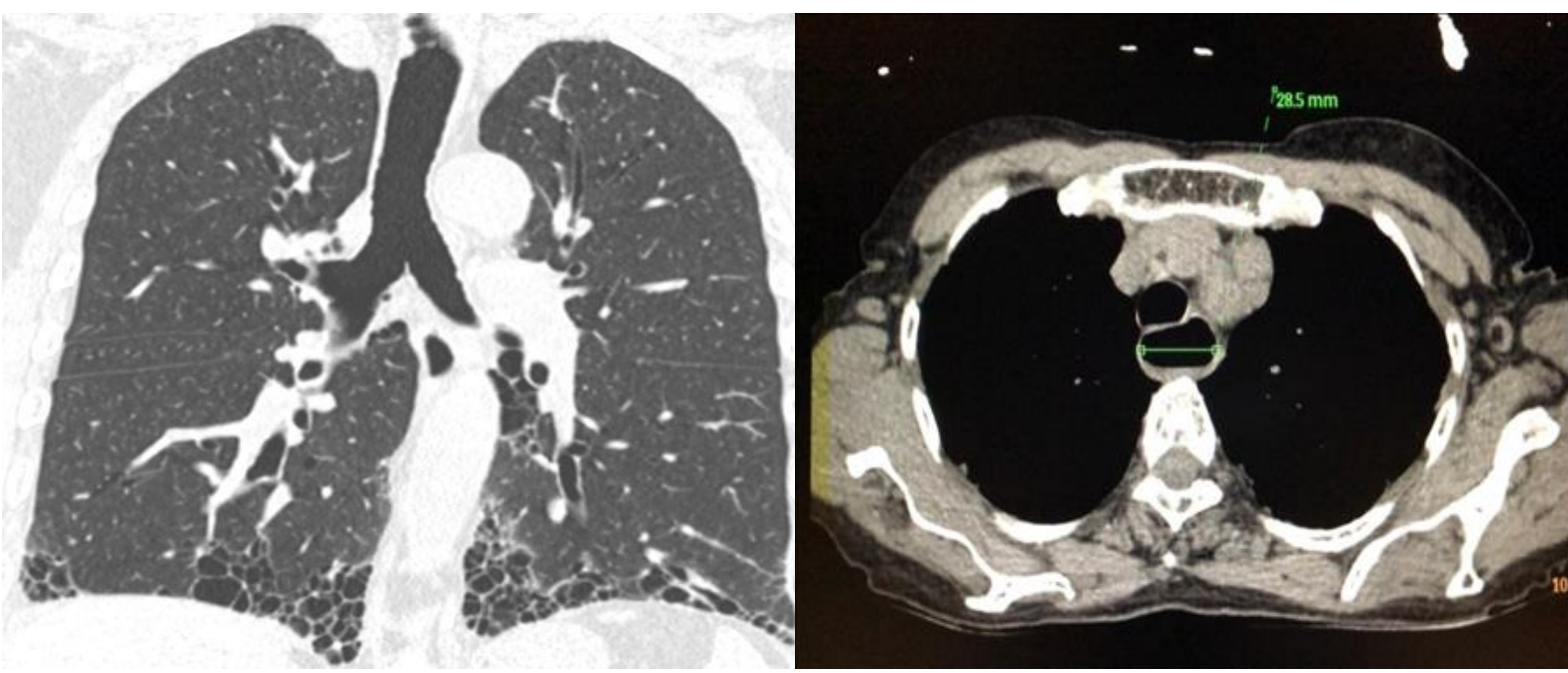

Figure 3: Coronal HRCT showing UIP Figure 4: Axial CT mediastinal window pattern-Honeycombing and reticular showing oesophageal dilatation in a case opacities in lower lobes without subpleural of systemic sclerosis. sparing. 


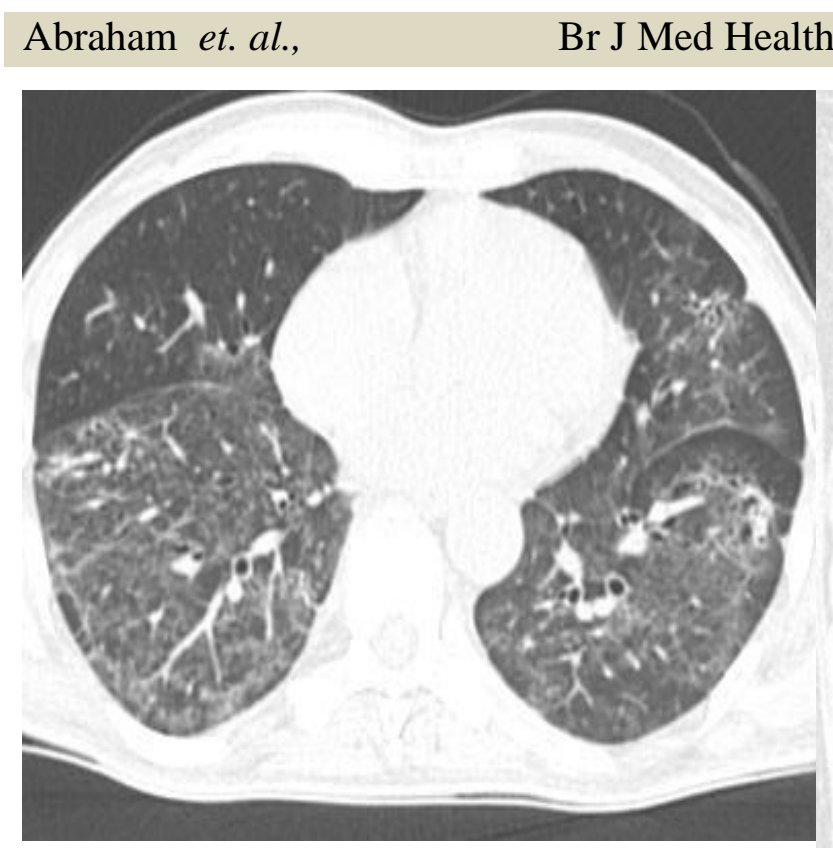

Figure 5: Axial HRCT showing NSIP Figure 6: Coronal HRCT showing LIP pattern with bilateral ground glass pattern with multiple lung cysts opacities with subpleural sparing

\section{Connective tissue disorders with their common HRCT findings}

Reticular opacities were the most common HRCT finding in RA seen in 18 patients $(69.2 \%)$ which was followed by bronchiectasis which was seen in 17 patients (Ref:table-3). Significantly higher incidence of UIP pattern (Ref: Figure 3) was noted in RA as compared to other connective tissue disorders.

Table: 3 HRCT findings in the study participants.

\begin{tabular}{|c|c|c|c|c|c|c|c|}
\hline HRCT findings & $\mathbf{R A}$ & SLE & $\begin{array}{l}\text { Sjogren's } \\
\text { syndrome }\end{array}$ & $\begin{array}{l}\text { DM- } \\
\text { PM }\end{array}$ & MCTD & Scleroderma & Total \\
\hline Reticular opacities & 18 & 5 & 2 & 2 & 3 & 7 & 37 \\
\hline Ground glass opacity & 11 & 4 & 3 & 4 & 4 & 8 & 34 \\
\hline Honeycombing & 8 & & 1 & 1 & 1 & 4 & 15 \\
\hline Nodules & 1 & & & 1 & & & 2 \\
\hline Consolidation & 1 & 1 & & 2 & 1 & & 5 \\
\hline Cysts & 1 & & 1 & & & & 2 \\
\hline Bronchiectasis & 17 & 2 & 1 & 1 & 1 & 3 & 25 \\
\hline Emphysema & 2 & 1 & & & & 1 & 4 \\
\hline Pleural effusion & & 6 & & & 1 & 1 & 8 \\
\hline Pleural thickening & & 2 & & & & & 2 \\
\hline $\begin{array}{l}\text { Pulmonary artery } \\
\text { dilatation }\end{array}$ & 2 & & & & & 1 & 3 \\
\hline Lymphadenopathy & & & & & & 1 & 1 \\
\hline $\begin{array}{l}\text { Esophageal } \\
\text { dilatation }\end{array}$ & & & & & & 7 & 7 \\
\hline
\end{tabular}

There were 13 patients of SLE evaluated in whom pleural effusion was the most common HRCT finding which was seen in 6 patients $(46.1 \%)$. This was followed by reticular opacities which was seen in 5 patients $(38.4 \%)$. 
Nine patients with Primary Systemic Sclerosis were present in the study and the most common finding was ground glass opacities which was seen in $88.9 \%$ patients. The frequency of esophageal dilatation (Ref: Figure 4) was found to be significantly higher in Primary Systemic Sclerosis as compared to other CTD in this study. All of the 4 MCTD patients showed ground glass opacities which was followed by reticular opacities seen in 3 patients (75\%).

All of the 4 Dermatomyositis-Polymyositis patients had ground glass opacities which was followed by reticular opacities and consolidation, which were noted in 2 patients each $(50 \%)$. The most common finding in Sjögren's syndrome patients was ground glass opacities which were seen in 3 patients $(75 \%)$. (Ref table 3 )

Table 4: Patterns of ILD in different connective tissue disorders.

\begin{tabular}{llllll}
\hline CTD & NSIP & UIP & OP & LIP & DAD \\
\hline Rheumatoid arthritis & 7 & 8 & 1 & 1 & 0 \\
Systemic Lupus Erythematosis & 4 & 1 & 0 & 0 & 1 \\
Primary Systemic sclerosis & 4 & 1 & 0 & 0 & 0 \\
Sjogren's syndrome & 1 & 0 & 0 & 1 & 0 \\
Mixed connective tissue disorder & 2 & 0 & 1 & 0 & 0 \\
Dermatomyositis-Polymyositis & 2 & 0 & 1 & 0 & 0 \\
P VALUE & 0.6602 & 0.3331 & 0.2850 & 0.1292 & 0.3987 \\
\hline
\end{tabular}

Most common ILD pattern was NSIP (33\%), (Ref figure 5) followed by UIP (16.7\%) pattern (Ref figure 3). But significantly higher incidence of UIP pattern was noted in RA as compared to other connective tissue disorders. There is also significantly high frequency of bronchectatic changes in RA patients. LIP pattern (Ref figure 6) was seen in one patents each with RA and Sjögren's Syndrome.

There is significantly high percentage of pleural effusion in patients presenting with SLE. There is also significantly higher occurrence of esophageal dilatation in patients with systemic sclerosis. There is considerable overlap of the pulmonary involvement patterns in different connective tissue disorders studied.

There is no statistically significant correlation between the ILD patters and any connective tissue disorders as $\mathrm{p}$ value is more than 0.05 suggesting overlapping of presentation by the diseases of connective tissue spectrum.

A female preponderance of 4:1 was noted in the study. Breathlessness was the most common presenting symptom. The mean age of the patients is 54.7years. Of the RA patients the most common finding was reticular opacities which were seen in 18 patients (69.2\%). The most common finding among SLE patients was pleural effusion seen in 6 patients (46.1\%).

Most common HRCT thorax finding in systemic sclerosis was ground glass opacities which was seen in 8 patients $(88.8 \%)$. Oesophageal dilatation was seen in 7 patients with systemic sclerosis (77.7\%). Most common HRCT thorax finding in Sjögren's Syndrome was ground 
glass opacities which were seen in 3 patients (75\%). Most common HRCT thorax finding in MCTD was ground glass opacities.

The female preponderance of 4:1 was similar to study conducted by Galhotra et $\mathrm{al}^{7}$ in 2018 (which showed that $82.9 \%$ of the patients were females) and by Afeltra et al ${ }^{8}$ in 2006.

The previous studies conducted by S.K.Verma et al ${ }^{9}$ in 2013 (in which $80 \%$ presented with breathlessness) and by Galhotra et $\mathrm{al}^{7}$ in 2018 found breathlessness as the most common presenting symptom which is in agreement with the present study.

The mean age of the patients is 54.7 years in agreement with the study by Bilgici et al (2004) ${ }^{10}$ giving mean age 53.6 years.

In the present study, among the RA patients the most common finding was reticular opacities which correlates with the previous studies conducted by Galhotra et al ${ }^{6}$ in 2018 which showed similar frequency of reticular opacities $(66.7 \%)$ and other studies done by Biederer et al ${ }^{10}$ in 2004 and Mohd Noor et al ${ }^{12}$ in 2009.

In the present study, among the SLE patients was pleural effusion seen in $46.1 \%$ of patients (This is in accordance with the previous study conducted by S.K.Verma et $\mathrm{al}^{7}$ in 2013 and Alamoudi et $\mathrm{al}^{13}$ (2015). In study conducted by Ping Li et al ${ }^{14}$ (2016) ground glass opacities were obtained in $30.77 \%$ of the patients with SLE which is in close concordance with the present study.

Most common HRCT thorax finding in systemic sclerosis was ground glass opacities which is in concordance with the study conducted by Goldin et $\mathrm{al}^{15}$ in 2008 which showed similar frequency $(91.2 \%)$ of ground glass opacities.

Oesophageal dilatation was seen in 7 patients with systemic sclerosis (77.7\%). Similar result were obtained by studies of Bhalla et $\mathrm{al}^{16}$ in (80\%). and Vonk et $\mathrm{al}^{17}$. in 2008, (83\%). Maghrapy et $\mathrm{al}^{18}$ (2013), in his study showed $90 \%$ frequency of ground glass opacities in Primary Systemic Sclerosis.

In the present study, among the Sjögren's Syndrome patients the most common finding was ground glass opacities which was seen in 3 patients $(75 \%)$ in agreement with Parambil et $\mathrm{al}^{19}$ study in 2006.

Most common HRCT thorax finding in MCTD was ground glass opacities. The studies conducted by S.K.Verma et al in 2013 and Kozhuka et $\mathrm{al}^{20}$ in 2001 showed similar frequency of GGO.

\section{CONCLUSION}

Significantly higher incidence of UIP pattern was noted in RA as compared to other connective tissue disorders. There is also significantly high frequency of bronchectatic changes in RA patients. There is significantly high percentage of pleural effusion in patients presenting with 
SLE. There is also significantly higher occurrence of oesophageal dilatation in patients with systemic sclerosis. There is considerable overlap of the pulmonary involvement patterns in different connective tissue disorders studied.

\section{LIST OF ABBREVIATIONS}

RA- Rheumatoid arthritis

SLE- Systemic Lupus Erythematosus

SS- Primary Sjögren's syndrome

PSS- Primary systemic sclerosis

PM-DM- Polymyositis-Dermatomyositis

MCTD- Mixed Connective Tissue Disease

HRCT- High Resolution Computed Tomography.

UIP-Usual Interstitial Pneumonia

NSIP-Non Specific Interstitial Pneumonia

OP-Organizing Pneumonia

LIP-Lymphoid Interstitial Pneumonia.

DAD- Diffuyse Alveolar Damage.

Connective Tissue Diseases - CTD

\section{REFERENCES}

1. Henry TS, Little BP, Veeraraghavan S, Bhalla S, Elicker BM. The spectrum of interstitial lung disease in connective tissue disease. Journal of thoracic imaging. 2016 Mar 1; 31(2):65-77.

2. El-Gabalawy H. Common denominators of inflammatory joint diseases. The Journal of Rheumatology Supplement. 2005 Jan 1; 72:3-6.

3. Woodhead F, Wells AU, Desai SR. Pulmonary complications of connective tissue diseases. Clin Chest Med. 2008; 29(1):149-64, vii. [PubMed] [Google Scholar]

4. Haaga JR, Boll D. Computed Tomography \& Magnetic Resonance Imaging of the Whole Body E-Book. Elsevier Health Sciences; 2016 Jun 6.(949-950)

5. Mittoo S, Gelber AC, Christopher-Stine L, Horton MR, Lechtzin N, Danoff SK. Ascertainment of collagen vascular disease in patients presenting with interstitial lung disease. Respiratory medicine. 2009 Aug 1;103(8):1152-8.

6. Mirfeizi Z, Farrokh D, Javanbakht A, Raufi E. Chest high resolution computed tomography findings in connective tissue diseases. Tanaffos. 2013;12(3):49-52.

7. Chopra A. Disease burden of rheumatic diseases in India: COPCORD perspective. indian journal of rheumatology. 2015 Jun 1;10(2):70-7.. 
8. Galhotra RD, Singh G, Saggar K, Saggar K, Gupta K. Primary Thoracic Manifestations in Connective Tissue Diseases on High Resolution Computed Tomography: A Prospective Study. Cough.;30(76.90):76-90- 2018.

9. Afeltra A, Zennaro D, Garzia P, Gigante A, Vadacca M, Ruggiero A, Dardes N, Navajas MF, Zobel BB, Amoroso A. Prevalence of interstitial lung involvement in patients with connective tissue diseases assessed with high-resolution computed tomography. Scandinavian journal of rheumatology. 2006 Jan 1;35(5):388-94.

10. Verma SK, Saheer S, Kumar P, Kumar M, Das SK, Prasad R, Hassan G. Respiratory manifestations among patients with connective tissue disorders. Journal, Indian Academy of Clinical Medicine. 2013 Jan; 14(1):29.

11. Bilgici A, Ulusoy H, Kuru O, Celenk C, Ünsal M, Danacı M. Pulmonary involvement in rheumatoid arthritis. Rheumatology international. 2005 Sep 1; 25(6):429-35.

12. Biederer J, Schnabel A, Muhle C, Gross WL, Heller M, Reuter M. Correlation between HRCT findings, pulmonary function tests and bronchoalveolar lavage cytology in interstitial lung disease associated with rheumatoid arthritis. European radiology. 2004 Feb 1; 14(2):272-80.

13. N.Mohd Noor,M.S Mohd Shahrir, M.S Shahid. R Abdul Manap, A.M. Shahizon Azura and S. A Shah- Clinical and high resolution computed tomography characteristics of patients with rheumatoid arthritis lung disease- International Journal of Rheumatic Diseases 2009; 12: 136-144

14. Alamoudi OS, Attar SM. Pulmonary manifestations in systemic lupus erythematosus: association with disease activity. Respirology. 2015 Apr;20(3):474-80.

15. Li P, Li S, Li L, Wang M. Chest CT findings in systemic lupus erythematosus and its correlation with serum markers. Radiology of Infectious Diseases. 2017 Mar 1;4(1):713.

16. Goldin JG, Lynch DA, Strollo DC, Suh RD, Schraufnagel DE, Clements PJ, Elashoff RM, Furst DE, Vasunilashorn S, McNitt-Gray MF, Brown MS. High-resolution CT scan findings in patients with symptomatic scleroderma-related interstitial lung disease. Chest. 2008 Aug 1;134(2):358-67.

17. Bhalla ME, Silver RM, Shepard JA, McLoud TC. Chest CT in patients with scleroderma: prevalence of asymptomatic esophageal dilatation and mediastinal lymphadenopathy. AJR. American journal of roentgenology. 1993 Aug;161(2):269-72.

18. Vonk MC, Van Die CE, Snoeren MM, Bhansing KJ, van Riel PL, Fransen J, van den Hoogen FH. Oesophageal dilatation on high-resolution computed tomography scan of the lungs as a sign of scleroderma. Annals of the rheumatic diseases. 2008 Sep $1 ; 67(9): 1317-21$ 
19. Maghrapy HM, Mohamed RA, Abdelaziz E. Assessment of Pulmonary Manifestations Of Collagen Diseases: High Resolution Computed Tomography Findings. AAMJ, VOL10, NO4, OCT 2013

20. Parambil JG, Myers JL, Ryu JH. Diffuse alveolar damage: uncommon manifestation of pulmonary involvement in patients with connective tissue diseases. Chest. 2006 Aug $1 ; 130(2): 553-8$.

21. Owlia MB. Clinical spectrum of connective tissue disorders. Journal, Indian Academy of Clinical Medicine. 2006 Jul;7(3):217-24.

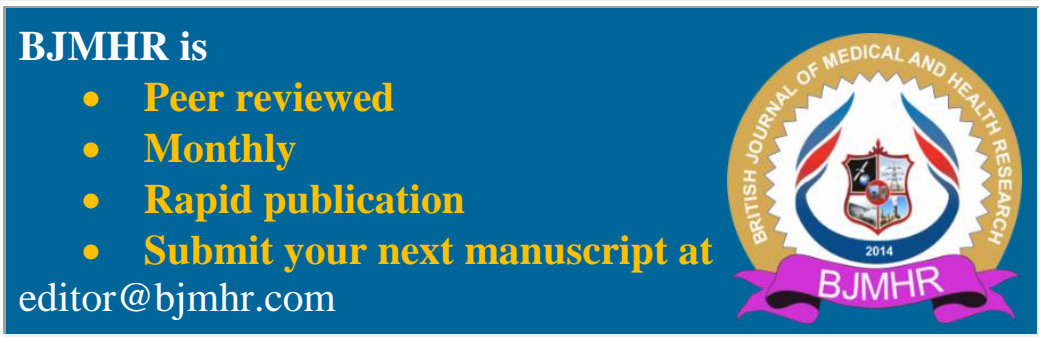

